\title{
Regime especial de atividades não presenciais: a pandemia acentuando as desigualdades na educação infantil
}

\author{
Special Regime of Non-Attendance Activities: \\ covid19 pandemic deepening inequalities in early childhood education \\ Régime spécial d'activités non présentielles: \\ pandémie accentuant les inégalités dans l'éducation des enfants
}

João Vitor Santos Silva ${ }^{1}$

Universidade Federal de Uberlândia

Klívia de Cássia Silva Nunes ${ }^{2}$

Universidade Federal de Uberlândia

Raquel Aparecida Souza ${ }^{3}$

Universidade Federal de Uberlândia

Rogéria Moreira Rezende Isobe 4 Universidade Federal do Triângulo Mineiro

Valéria Moreira Rezende ${ }^{5}$ Universidade Federal de Uberlândia

Resumo: $\mathrm{O}$ artigo resulta de pesquisa que teve como objetivo analisar a oferta do Regime Especial de Atividades Não Presenciais (REANP) para a educação infantil, a partir da percepção das professoras de escolas públicas do município de Santa Vitória, Minas Gerais. A pesquisa qualitativa utilizou-se do questionário para coleta de dados. Os resultados apontam inúmeros desafios enfrentados pelas docentes dentre os quais a falta de condições objetivas para viabilizar o ensino, uma vez que muitos professores e alunos não têm acesso à internet de qualidade e nem sempre possuem o domínio no manejo de aplicativos e plataformas digitais. Concluímos que o ensino não presencial deflagra o notório processo de exclusão digital em decorrência da exacerbada desigualdade social que marca a sociedade brasileira.

Palavras-chave: Educação Infantil. Regime Especial de Atividades Não Presenciais. Tecnologias digitais. Desigualdade social.

\footnotetext{
${ }^{1}$ Graduando em Pedagogia. Universidade Federal de Uberlândia. Ituiutaba-MG, Brasil. E-mail: vitorconfessor27@gmail.com.ORCID: https://orcid.org/oooo-0003-3139-8704.

${ }^{2}$ Doutorado em Educação. Universidade Federal de Uberlândia. Ituiutaba-MG, Brasil. E-mail: klivia.nunes@ufu.br. Lattes: http://lattes.cnpq.br/9412398959184082. ORCID: https://orcid.org/O000-0001-5264-9598.

${ }^{3}$ Doutorado em Educação. Universidade Federal de Uberlândia. Ituiutaba - MG, Brasil. E-mail: raquelas@ufu.br. Lattes: http://lattes.cnpq.br/9208469507359517. ORCID: https://orcid.org/o000-0001-5906-0671.

${ }^{4}$ Doutorado em Educação. Universidade Federal do Triângulo Mineiro. Uberaba-MG, Brasil. E-mail: rogeria.isobe@uftm.edu.br._ Lattes:_http://lattes.cnpq.br/5970509404713363. ORCID: https://orcid.org/0000-0002-4762-9100.

${ }^{5}$ Doutorado em Educação. Universidade Federal de Uberlândia. Ituiutaba-MG, Brasil. E-mail: valeria.rezende@ufu.br. Lattes: http://lattes.cnpq.br/1154586418090576. ORCID: https://orcid.org/O000-0002-2686-956X.
} 
Abstract: This article is the result of a research that aimed to analyze the offer of the Special Regime of Non-Attendance Activities (distance learning) for early childhood education, from the perception of public-school teachers in Santa Vitória, a town in Minas Gerais. It was a qualitative research and the questionnaire was used for data collection. The results point to numerous challenges faced by teachers, among which the lack of objective conditions to make teaching viable must be highlighted since many teachers and students do not have access to quality internet and cannot always deal with digital applications and IT platforms. We conclude that distance learning triggers the notorious process of digital exclusion because of the exacerbated social inequality in Brazilian society.

Keywords: Early Childhood Education. Special Regime for Non-Attendance Activities. Digital technologies. Social inequality.

Résumé: L'article est le résultat de recherches qui ont eu pour but d'analyser l'offre du Régime spécial d'activités non présentes (REANP) pour l'éducation des enfants, à partir de la perception des enseignantes des écoles publiques de la municipalité de Santa Victoria, Minas Gerais. La recherche qualitative a été utilisée dans le questionnaire pour la collecte des données. Les résultats montrent de nombreux défis auxquels sont confrontées les enseignants, parmi lesquels l'absence de conditions objectives pour permettre l'enseignement, étant donné que de nombreux enseignants et élèves n'ont pas accès à l'internet de qualité et ne maîtrisent pas toujours les applications et les plates-formes numériques. Nous en sommes arrivés à la conclusion que l'enseignement non présentiel déclenche le processus notoire d'exclusion numérique en raison de l'inégalité sociale exacerbée qui marque la société brésilienne.

Mots-clés: L'éducation des enfants. Régime spécial pour les activités de non-participation. Technologies numériques. Inégalité sociale.

Recebido em: 10 de junho de 2021 Aceito em: 01 de agosto de 2021

\section{Introdução}

A educação infantil, assim como todos os outros níveis e modalidades de educação no Brasil e no mundo, teve suas atividades presenciais suspensas em março de 2020 como medida de proteção contra a disseminação do vírus SARS-CoV-2, causador da Covid-19, que se tornou uma pandemia com níveis alarmantes de contaminação, apresentando-se como um dos maiores desafios sanitários em escala global deste século.

A pandemia tomou conta de praticamente todos os países do mundo mas, apresenta-se com impactos diferentes conforme estratégias de enfrentamento adotadas em cada país. No caso do Brasil, após a declaração da OMS (Organização Mundial de Saúde), em 11 de março de 2020, sobre a disseminação comunitária da Covid-19 - que decreta situação de pandemia no que se refere à infecção pelo novo coronavírus - o governo brasileiro editou vários documentos legais para enfrentamento da emergência em saúde pública. Destaca-se a Portaria 
do Ministério da Educação n 343, de 17 de março de 2020 (BRASIL, 2020), que dispõe sobre a substituição das aulas presenciais por aulas com meios digitais enquanto durar a situação de pandemia do Novo Coronavírus.

Nessa conjuntura, Estados e Municípios editaram decretos e outros instrumentos legais e normativos para o enfrentamento da emergência de saúde pública, estando, dentre eles, a suspensão das atividades escolares. O estado de Minas Gerais aderiu à suspensão das aulas presenciais pela Deliberação n ${ }^{\circ}$ 18, de 21 de março de 2020, do Comitê Extraordinário de COVID-19 (MINAS GERAIS, 2020) e as instituições escolares públicas e privadas precisaram se organizar para fazer a oferta do ensino remoto emergencial.

É nesse contexto que estamos desenvolvendo a pesquisa intitulada: "Intercorrências do trabalho docente na educação básica em tempos de pandemia: o retrato da microrregião do Pontal do Triângulo Mineiro”, com o objetivo de refletir sobre os impactos e desafios do ensino não presencial na educação básica em nível regional. A pesquisa, ainda em desenvolvimento, está sendo realizada em oito munícipios da microrregião do Triângulo Mineiro, compondo um levantamento diagnóstico em parceria com o Observatório Educacional em Rede (OER), o Grupo de Estudos e Pesquisas em Políticas, Formação docente e práticas educativas (Geppope), e o Núcleo de Estudos e Pesquisas em Formação e Trabalho Docente: Políticas e Práticas Educacionais (Nuforpe) da Universidade Federal de Uberlândia.

Como recorte da pesquisa este artigo apresenta resultados obtidos pela coleta de dados em escolas públicas de educação infantil localizadas no município de Santa Vitória - que faz parte da microrregião pesquisada - com a finalidade de analisar a percepção das professoras ${ }^{6}$ sobre a oferta do ensino não presencial para a educação infantil. A denominação para esse formato de ensino que será utilizada nesse artigo é de Regime Especial de Atividades Não Presenciais (REANP), nomenclatura adotada pelo município de Santa Vitória por meio do Decreto PM/nº 9.205 de 16 de outubro de 2020 (SANTA VITÓRIA, 2020).

A pesquisa de abordagem qualitativa, baseada no método descritivo, utilizou o questionário virtual para coleta de dados e foi dividida em cinco seções: Termo de consentimento livre e esclarecido; Dados pessoais e profissionais; Educação infantil na pandemia (três questões fechadas com a opção “outros” para justificar e uma aberta); Trabalho docente na pandemia (seis questões fechadas com a opção "outros” para justificar e quatro abertas; e Tecnologia digital e formação com duas questões fechadas, com a opção "outros” para

\footnotetext{
${ }^{6}$ A adoção pelo gênero feminino deve-se ao fato de que as participantes da pesquisa são todas mulheres.
} 
justificar, e duas questões abertas. Participaram da investigação 24 professoras de 10 escolas públicas da rede municipal de ensino da cidade mencionada.

\section{Desigualdades sociais e educacionais potencializadas na pandemia}

Em 2021 estamos vivenciando um contexto atípico na vida social, sobretudo na educação. Muitas instituições escolares permanecem com as atividades formativas não presenciais e outras já iniciaram experiências no formato semipresencial, sendo que a grande maioria tem utilizado tecnologias digitais para desenvolver o processo educativo. Por sua vez, vê-se que essas ações exigem, da comunidade escolar, mudanças na maneira de organizar o cotidiano educacional.

No conjunto de mazelas e prejuízos causados pela Covid-19 tem-se a questão do isolamento social que se fez necessário como medida protetiva para ajudar a conter o aumento na disseminação da transmissão do vírus. Também houve a suspensão de muitos serviços sociais como o trabalho em diversos setores, lojas e comércios, e as aulas presenciais, dentre tantas outras atividades que não puderam ser realizadas de forma presencial desde março de 2020. Essas medidas têm impactado e contribuído diretamente para o aumento da desigualdade social no país porque houve o crescimento do número de pessoas desempregadas, da taxa do crescimento da pobreza e, consequentemente, o aumento da desigualdade educacional.

No caso do Brasil, especificamente, é importante problematizar o atual contexto do século XXI, mais precisamente a partir de 2016, em que vários estudiosos apontam que fomos vítimas de um golpe midiático, jurídico e parlamentar, em decorrência do impeachment da presidenta Dilma Rousseff e da ascensão ao poder do seu vice-presidente Michel Temer. Tal fenômeno gerou incertezas, inseguranças e instabilidades políticas, econômicas, sociais, sanitárias e educacionais em todo o país.

Krawczyk e Lombardi (2018) organizaram uma reflexão sobre essas questões no livro intitulado: "O golpe de 2016 e a educação no Brasil". Entre outros temas, os autores destacam a reorganização imperialista em tempo de globalização; a crise política e o papel da educação na resistência ao golpe de 2016 no Brasil; a mercantilização da educação; a reforma trabalhista e os professores; e a formação de professores e gestão escolar.

Somando-se às consequências vividas nesse período, entra também o contexto de pandemia a partir de 2020, em que se amplia um cenário de muita fragilidade, o qual expõe mazelas que estavam, em certa medida, invisíveis aos olhos da população, mas que são sobejamente sentidas por mais de 51,9 milhões de brasileiros vivendo abaixo da linha da pobreza (FLACSO, 2021). Isso se traduz em grandes injustiças potencializadas pelo sistema 
capitalista em seu modelo vigente. Milhões de brasileiros passam fome, sobrevivem em condições precárias de subsistência, sem condições de ter acesso básico à saúde, educação, moradia e segurança. A desigualdade social tem se mostrado cada vez mais evidente no Brasil, revelando a garra predatória da atual política, potencializada pelo agravamento do pós-2016.

Ao ponderar que muitos desses desafios poderiam ter sido evitados, Paro (2020) argumenta que com o desenvolvimento das forças produtivas, construídas historicamente, o país é capaz de produzir alimentos e proporcionar melhores condições de vida para todos. Uma das possibilidades de superação deste cenário é a mudança da infraestrutura - a base econômica capitalista - por meio de lutas sociais em busca de um novo modo de produção. A busca do lucro exacerbado, presente nesse modelo capitalista, promove a necessidade do consumo acima de tudo, levando milhões de brasileiros a viverem na pobreza.

O IBGE divulgou no dia 30 de abril a taxa de desocupação referente ao trimestre móvel de dezembro de 2020 a fevereiro de 2021 . Eram 14,4 milhões de pessoas desocupadas. A taxa é recorde da série histórica iniciada em 2012. Isso demonstra um cenário frágil do mercado de trabalho. Aliás, desde o início da pandemia, o número de pessoas sem emprego no Brasil aumentou $16,9 \%$, e teve ainda um acréscimo de 2,1 milhões de pessoas em busca de trabalho, segundo o Instituto (GEMAQUE, 2020, s/p).

Esse dado aponta o agravamento do desemprego na pandemia, o que reforça as evidências de que embora a Covid-19 atinja todas as classes sociais, assola, de forma mais intensa, os grupos vulneráveis. A população de baixa renda não tem a opção de permanecer em isolamento e ficar em casa pois precisa trabalhar a fim de garantir o sustento da família.

Outro dado importante a ser considerado é a pesquisa realizada pelo Fundo das Nações Unidas para a Infância (UNICEF), em parceria com o Centro de Estudos e Pesquisas em Educação, Cultura e Ação Comunitária (CENPEC), a qual indica que mais de cinco milhões de crianças e adolescentes, entre 6 e 10 anos, estavam sem acesso aos estudos no Brasil no fim de 2020. A pesquisa revela que:

Com escolas fechadas por causa da pandemia, em novembro de 2020, quase 1,5 milhão de crianças e adolescentes de 6 a 17 anos não frequentavam a escola (remota ou presencialmente). A eles somam-se outros 3,7 milhões que estavam matriculados, mas não tiveram acesso a atividades escolares e não conseguiram se manter aprendendo em casa. No total, 5,1 milhões tiveram seu direito à educação negado em novembro de 2020. Crianças de 6 a 10 anos sem acesso à educação eram exceção no Brasil antes da pandemia. Essa mudança observada em 2020 pode ter impactos em toda uma geração. São crianças dos anos iniciais do ensino fundamental, fase de alfabetização e outras aprendizagens essenciais às demais etapas escolares. Ciclos de alfabetização incompletos podem acarretar reprovações e abandono escolar. É urgente reabrir as escolas, e mantê-las abertas, em segurança”, defende Florence Bauer, representante do UNICEF no Brasil (UNICEF, 2021). 
Esse cenário deflagra, de modo escancarado, as desigualdades educacionais sendo que o índice de crianças e adolescentes excluídos do sistema escolar aumentou com a situação de pandemia. O direito à educação é negado também quando não há a garantia de um eficiente processo de ensino e aprendizagem, como mostra a pesquisa sobre o efeito do ensino remoto ${ }^{7}$ para os estudantes (FUNDAÇÃO CARLOS CHAGAS, 2020), cujos dados se expressam na figura abaixo:

Figura 1: Efeito da suspensão das aulas presenciais para os alunos

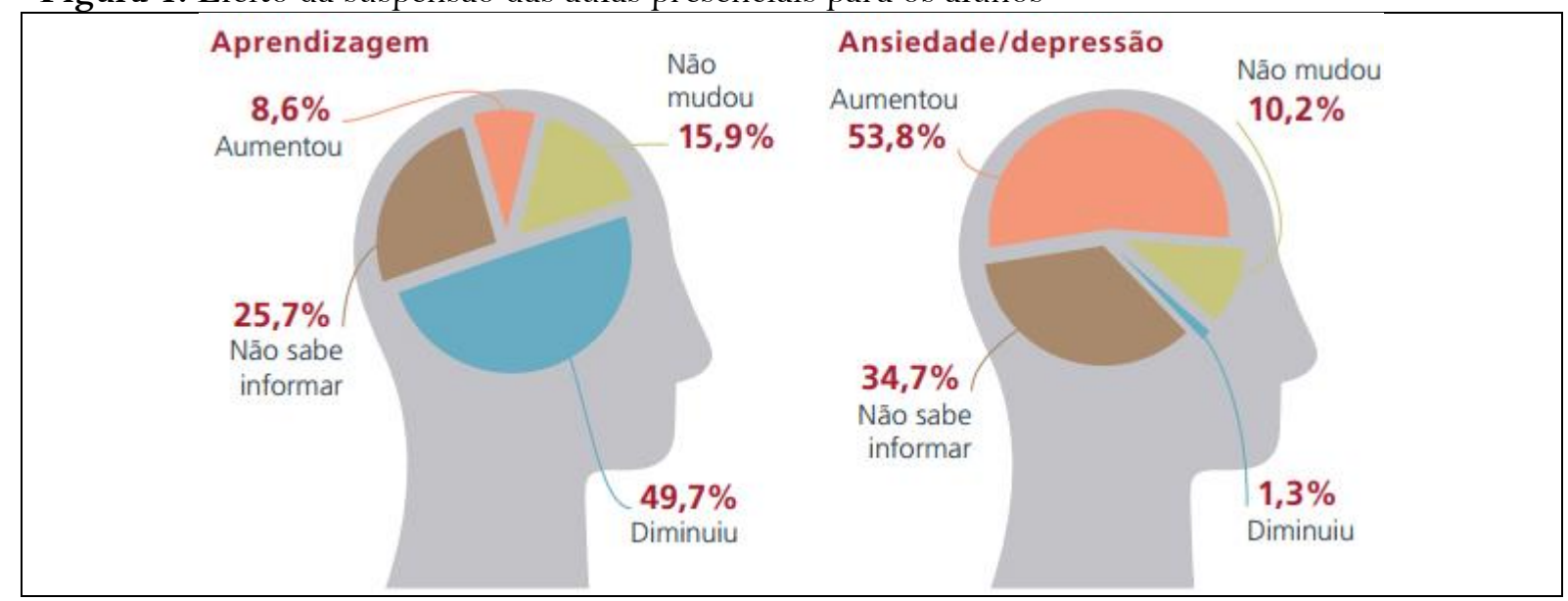

Fonte: Fundação Carlos Chagas, 2020.

Os dados mais expressivos indicam que $49,7 \%$ dos professores consideram que a aprendizagem dos estudantes diminuiu e 53,8\% consideraram um aumento do nível de ansiedade e depressão. Um dos aspectos a ser ressaltado é que essa nova realidade exige que professores e alunos tenham acesso a recursos tecnológicos que viabilizem o processo ensino-aprendizagem de forma não presencial. No entanto, estudo feito por Oliveira e Pereira Júnior (2020, p. 731) revela que 2 , de cada 3 alunos, não têm acesso a tais recursos e que "a parcela de professores que não os possuem é de $17,4 \%$, ao passo que atinge $66,2 \%$ entre os estudantes”.

Os dados corroboram a tese de que no Brasil não se teve uma política efetiva de coordenação nacional expressiva para conduzir e orientar quanto aos caminhos que deveriam ser tomados tanto na saúde pública, quanto na educação. De forma geral as iniciativas foram tomadas pelos gestores dos estados e municípios, de forma conjunta ou não, de modo a encontrar alternativas para conter a disseminação da doença e, por sua vez, fazendo tentativas com o REANP. No entanto, a flagrante desigualdade social resulta em um abismo entre o sujeito e o acesso às condições objetivas para o ensino e a aprendizagem de qualidade.

\footnotetext{
${ }^{7}$ Hodges et al apresentam uma importante contribuição sobre o termo "ensino remoto", destacando que se trata de uma mudança temporária da entrega de instruções para um modo de entrega alternativo devido a circunstâncias de crise. Envolve o uso de soluções de ensino totalmente remotas para instrução ou educação que, de outra forma, seriam ministradas essencialmente, ou como cursos combinados ou híbridos, e que retornarão a esse formato assim que a crise ou emergência tiver diminuído (2020, p. 05)
} 
Para caracterização desse nível de pobreza escancarada na pandemia, tomamos de Montaño (2012) os conceitos de pobreza pré-capitalista e capitalista:

[...] em sociedades pré-capitalistas a pobreza é o resultado (para além da desigualdade na distribuição da riqueza) do insuficiente desenvolvimento da produção de bens de consumo, ou seja, da escassez de produtos [...]. Contrariamente, no modo de produção capitalista a pobreza (pauperização absoluta ou relativa, conforme caracteriza Marx, 1980, I, p. 747 e 717) é o resultado da acumulação privada de capital, mediante a exploração (da maisvalia) na relação entre capital e trabalho, entre donos dos meios de produção e donos de mera força de trabalho, exploradores e explorados, produtores diretos de riqueza e usurpadores do trabalho alheio. [...] Quanto mais riqueza produz o trabalhador, maior é a exploração, mais riqueza é expropriada (do trabalhador) e apropriada (pelo capital). Assim, não é a escassez que gera a pobreza, mas a abundância (concentrada a riqueza em poucas mãos) que gera desigualdade e pauperização absoluta e relativa (MONTAÑO, 2012, p. 279).

Considera-se que quanto mais se desenvolve o modo de produção capitalista, com maior acumulação do capital, mais há exploração das forças de trabalho da classe trabalhadora para a extração da mais-valia, que gera um círculo de acumulação de riqueza e, ao mesmo tempo, gera pobreza, o que quer dizer que "quanto mais riqueza produz o trabalhador, maior é a exploração, mais riqueza é expropriada (do trabalhador) e apropriada (pelo capital)” (MONTAÑO, 2012, 279). Nessa perspectiva, pode-se inferir que a abundância de concentração de riqueza nas mãos de poucos é que gera desigualdade e pauperização absoluta e relativa da maioria da população.

Para Marx (2013), o mercado funciona como um mecanismo de manutenção das desigualdades sociais em que os ricos ficam cada vez mais ricos, e os pobres tornam-se mais pobres. Fica sem perspectiva, na ordem do capital, reduzir qualquer distanciamento entre estes dois polos, pois a miséria é utilizada como um instrumento pelas classes dominantes para continuar dominando, explorando cada vez mais a classe trabalhadora. Ou seja, o fator "desenvolvimento" no capitalismo não promove maior distribuição de riqueza mas, sim, uma maior concentração de capital, portanto, maior empobrecimento (absoluto e relativo).

A partir desses olhares, fica evidente que o aumento das desigualdades educacionais no país foi potencializado com o advento da pandemia, embora já existissem antes dela. Diante da necessidade de suspensão das aulas presenciais e o acesso ao ensino não presencial, com a utilização de ferramentas tecnológicas, foram escancaradas as diferenças de acesso à educação, quando uma grande parcela dos alunos de escolas públicas não possuem condições mínimas de infraestrutura para acompanhamento das aulas.

Importa ressaltar que o acesso ao ensino não presencial se desenvolve de formas diferentes para alunos de escolas públicas e privadas, uma vez que os estudantes das escolas particulares têm melhores condições de infraestrutura para participarem das 
atividades. Já uma grande maioria dos alunos da educação pública não contam com recursos mínimos para acompanharem as aulas, o que contribui ainda mais para o aumento das desigualdades sociais e educacionais.

A utilização de tecnologias na educação, sobretudo na condição emergencial que estamos vivendo, tem sido questão essencial para auxiliar o processo de desenvolvimento do ensino e da aprendizagem. No entanto, as desigualdades educacionais existentes, mesmo antes da pandemia, têm sido potencializadas.

Estas atividades remotas no ensino público tiveram por objetivo estimular intelectualmente o aluno durante o isolamento, sendo esta adesão, em muitos casos, facultativa. Entretanto, muitos estudantes vivem em situação de vulnerabilidade com dificuldade no acesso à internet e estrutura tecnológica para o ensino remoto, dificultando a continuidade e o estímulo intelectual. (PRESTES, 2020. s/p)

A Pesquisa Nacional por Amostra de Domicílios Contínua TIC (IBGE, PNAD/TIC), realizada em 2019, demonstra dados importantes no que se refere ao acesso à internet e aos equipamentos eletrônicos utilizados por estudantes de escolas públicas e privadas:

[...] entre as 183,3 milhões de pessoas com 10 anos ou mais de idade no país, 143,5 milhões $(78,3 \%)$ utilizaram a internet nos últimos três meses. Jovens adultos entre 20 e 29 anos foram os que mais acessaram. O uso é maior entre estudantes $(88,1 \%)$ do que entre não estudantes $(75,8 \%)$. Os estudantes da rede privada (98,4\%) usam mais do que os da rede pública $(83,7 \%)$. Em 2019, $81,8 \%$ dos estudantes da rede privada acessavam a internet pelo computador, contra $43,0 \%$ da rede pública. O celular foi o principal equipamento utilizado para acessar a internet pelos estudantes nas redes pública $(96,8 \%)$ e privada $(98,5 \%)$. O percentual dos que fizeram chamadas de voz ou vídeo via internet subiu de $88,1 \%$ para $91,2 \%$ (IBGE, 2021).

Os dados do PNAD também revelam que em 2019 34,9 milhões de pessoas não tinham sequer o acesso a um celular e os motivos eram o alto custo do aparelho, bem como a dificuldade no manuseio e desinteresse.

As desigualdades sociais engendram desigualdades educacionais e revelam que o Brasil não tem infraestrutura básica para enfrentar uma situação de crise sanitária como a da pandemia da Covid-19. Embora haja discursos sobre a necessidades de inclusão digital, sabese que os investimentos, até então, foram insuficientes para dar conta de retirar milhares de estudantes e professores da condição de exclusão digital.

Os apontamentos acima mencionados auxiliam na compreensão de questões importantes sobre o desenvolvimento do REANP nesse contexto pandêmico, sobretudo na Educação Infantil no município de Santa Vitória. 


\section{Desvelando o ensino não presencial sob a ótica das professoras}

A faixa etária das 24 professoras participantes da pesquisa apresenta grande variação sendo que 9 docentes estão entre 31 a 40 anos, 6 estão entre 41 a 50 anos, 5 na faixa de 19 a 30 anos, 2 abaixo de 18 anos e 2 acima de 50 anos. Quanto à formação profissional 15 docentes possuem graduação em Pedagogia e 9 têm formação de nível médio na modalidade normal ${ }^{8}$. Já o tempo de atuação na educação infantil das respondentes varia de 1 a 21 anos.

No que diz respeito ao desenvolvimento do REANP na educação infantil, as docentes destacaram a questão da participação das famílias ressaltando que $75 \%$ participam ativamente da vida escolar dos filhos, mesmo que de forma precária, e $25 \%$ apresentaram a participação fraca e inconstante. De acordo com as professoras, as dificuldades das famílias incluem falta de acesso à internet, dificuldades com o uso do aplicativo WhatsApp, falta de equipamentos apropriados para o estudo, desinteresse pelo ensino não presencial e a falta de tempo para auxiliar nas atividades.

Sobre o envolvimento das crianças no REANP, 10 professoras informaram que a participação nas atividades gira em em torno de 41,7\%; 2 apontaram que a participação é de 90\%; 5 acreditam que somente 20,8\% participam; 6 afirmaram que houve um percentual de 25\% de participação nas atividades; e apenas 1 professora considerou que a participação é somente $10 \%$. Observa-se que nenhuma das professoras considerou a participação dos alunos em sua totalidade. Nos registros das questões abertas algumas docentes ressaltaram ainda que a participação das crianças é inconstante e resulta de muita insistência por parte da escola.

Podemos afirmar que esta inconstância, evidenciada nas percepções das professoras sobre a participação nas atividades desenvolvidas no formato não presencial, poderá contribuir para a fragilização do desenvolvimento das crianças no que tange ao processo de aquisição dos signos culturais decorrentes do processo educativo que se inicia na educação infantil (VIGOTSKII, 2010). Em relação à aprendizagem, é oportuno destacar que as crianças não aprendem todas da mesma forma, portanto, ao considerar as diversas inconstâncias nessa nova forma de ensinar, há que se considerar também diversas dificuldades para que se efetive esse processo (KRAMER, 2006).

A propósito, considerando essa questão, foi perguntado como as professoras avaliam a aprendizagem das crianças no REANP em relação ao ensino presencial. A maioria das

\footnotetext{
${ }^{8}$ Segundo o artigo 62 da LDB: “A formação de docentes para atuar na educação básica far-se-á em nível superior, em curso de licenciatura, de graduação plena, em universidades e institutos superiores de educação, admitida, como formação mínima para o exercício do magistério na educação infantil e nas quatro primeiras séries do ensino fundamental, a oferecida em nível médio, na modalidade normal”.
} 
respondentes, representando $87,5 \%$, avaliam ter havido uma diminuição de aprendizagem quando comparada ao ensino presencial, como se pode observar nos dados da tabela 1:

Tabela 1: Aprendizagem no REANP em relação ao ensino presencial

\begin{tabular}{|c|c|c|}
\hline Situação & Quantidade & $\%$ \\
\hline Não houve alteração & 1 & $4,1 \%$ \\
\hline As crianças aprendem mais do que no ensino presencial & 0 & 0 \\
\hline As crianças aprendem menos do que no ensino presencial & 21 & $87,5 \%$ \\
\hline Ainda não avaliei o aprendizado no ensino não presencial & 2 & 8,4 \\
\hline Total & 24 & 100 \\
\hline
\end{tabular}

Fonte: Elaborado pelos autores.

As docentes afirmam que têm buscado a reinvenção da prática para envolver as crianças nas atividades, utilizando estratégias de criação de grupos de WhatsApp para orientação, envio de links de vídeos, mensagens de voz, materiais complementares, entre outros. No entanto, por mais que busquem maneiras de tornar a aula mais atrativa, as professoras registraram situações em que as crianças não conseguem aprender questões básicas e essenciais da educação infantil nesse formato de ensino. A respeito dessa questão são pertinentes as observações de Saviani e Galvão (202 1):

O “ensino" remoto é empobrecido não apenas porque há uma "frieza" entre os participantes de uma atividade síncrona, dificultadas pelas questões tecnológicas. Seu esvaziamento se expressa na impossibilidade de se realizar um trabalho pedagógico sério com o aprofundamento dos conteúdos de ensino, uma vez que essa modalidade não comporta aulas que se valham de diferentes formas de abordagem e que tenham professores e alunos com os mesmos espaços, tempos e compartilhamentos da educação presencial (SAVIANI; GALVÃO, 2021, p. 42).

A assertiva acima nos leva a outro questionamento feito às professoras sobre o processo de ensino e aprendizagem das crianças que não tinham acesso à internet. Segundo elas, a medida adotada pela Secretaria Municipal de Educação foi garantir que os materiais impressos chegassem até as famílias para que as crianças fizessem as atividades em casa, como mostram os dados da tabela 2 :

Tabela 2: Atendimento às crianças que não têm acesso ao REANP

\begin{tabular}{l|c}
\hline \multicolumn{1}{c|}{ Medidas adotadas } & Respostas \\
\hline As famílias pegam o material das aulas nas escolas & 21 \\
\hline As escolas entregam o material das aulas nas casas dos alunos & 6 \\
\hline As crianças que não estão no ensino não presencial estão sem atendimento & 0 \\
\hline Atendimento via chamada telefônica & 1 \\
\hline
\end{tabular}

Fonte: Elaborado pelos autores. 
As professoras destacaram que a escola e os gestores estão realizando um intenso movimento de acompanhamento para que as crianças não fiquem sem atendimento. No entanto, as dificuldades não se restringem à falta de acesso à internet, mas também à falta de equipamentos para acessarem as orientações dos professores como aparelhos celulares para dar conta de toda a demanda familiar, uma vez que muitas famílias têm um único aparelho para atender duas ou mais crianças em idade escolar.

Há também outro ponto que vem ao encontro do que já foi tratado acima, no que se refere ao desenvolvimento das funções psicológicas, visto que este desenvolvimento requer dois movimentos interligados, o interpsíquico que se dá através da atividade coletiva e o intrapsíquico, o qual se refere como propriedade das atividades individuais (VIGOTSKI, 2010). A partir desse contexto, é preciso reafirmar sobre como se faz importante a valorização da figura do professor para o desenvolvimento da criança.

Isso significa que o indivíduo precisa aprender para se desenvolver e que isso se dá em primeiro lugar na relação com o outro. Vale dizer que esse "outro", na escola, é o professor, pois possui as condições de identificar as pendências afetivo-cognitivas que precisam ser suplantadas e que podem promover o desenvolvimento. Minimizar a função do educador na prática pedagógica é desqualificar a profissão e a profissionalidade da categoria docente, pois qualquer um, e em quaisquer condições precárias, poderia se arvorar a realizar o trabalho educativo escolar (SAVIANI; GALVÃO, 2021, p. 42. Grifo dos autores).

Associado a esses apontamentos, destaca-se, também, de acordo com as respostas das professoras, a questão da intensificação do trabalho docente, pois muitas delas além de fazer o planejamento, preparar as atividades, aprender a usar ferramentas, precisam também fazer atendimento online, na maioria das vezes por meio do aplicativo WhatsApp, de modo a auxiliar as famílias e os alunos para a entrega e correção das atividades. Muitas vezes isso se dá sem uma necessária interação para um efetivo processo de aprendizagem das crianças, tendo em vista que as questões burocráticas, o cansaço, e intenso tempo de dedicação às telas, têm sido impedimento para a construção de espaços pedagógicos mais eficientes.

O aumento da carga diária do trabalho dos professores é uma das consequências que esse formato de ensino tem apresentado. Para 17 das 24 professoras que responderam ao questionário, ficou evidenciado que essa carga de trabalho aumentou muito, 5 delas responderam que foi um aumento razoável e para 2 houve o entendimento que esse aumento foi pouco.

É perceptível que muitos professores compartilham esse sentimento não só no município em estudo, mas também em todo o país. Pesquisas mostram que muitos professores precisaram se adequar à uma nova realidade e isso implica em acompanhar as diferentes demandas que esse momento exige. Esse aumento fez-se presente na pesquisa realizada pelo 
Grupo de estudos sobre política educacional e trabalho docente - Gestrado (2020, p. 16): "O aumento das horas de trabalho gastas na preparação das aulas não presenciais ocorreu para a grande maioria”. Essa realidade se vê retratada na fala da professora: O meu tempo de trabalho, excedeu muito as horas do meu cargo. No início cheguei a trabalhar 18 horas, parando apenas para dormir. (Professora F da escola Alfa). Um dos argumentos para justificar esse aumento deve-se ao desconhecimento dos professores com os ambientes virtuais de aprendizagem e a pesquisa de Oliveira e Pereira Junior (2000, p. 732) aponta para essa realidade:

Os resultados mostram que a grande parte dos participantes da pesquisa, o equivalente a $82,4 \%$, afirmou que aumentou a quantidade de horas destinadas à preparação das aulas não presenciais [...]. Trata-se de uma informação de extrema relevância, pois mostra que os docentes passaram a assumir maior carga de trabalho para realizar o ensino de forma remota. Um dos possíveis fatores que contribuiu para o aumento da carga de trabalho é a pouca ou insuficiente formação dos profissionais para lidar com as tecnologias digitais. Os ambientes virtuais de aprendizagem ainda não são conhecidos pela maioria dos profissionais em exercício presencial nas escolas.

O aumento da carga de trabalho no preparo das atividades para o formato de ensino não presencial realizado por meio de plataformas digitais está atrelado a uma série de fatores que potencializam ainda mais a precarização do trabalho dos professores: a preocupação com a própria saúde física e mental; medo de perder o emprego ou renda; pressão constante para usar e se adaptar às ferramentas virtuais; a ansiedade causada pela necessidade de manter os alunos estimulados, mesmo sem contato direto com eles; dar assistência aos alunos que não conseguiram acompanhar as atividades propostas; mudança radical das rotinas pessoais e profissionais, pois tornou-se comum os professores tomarem o espaço e o tempo de casa para resolver questões de trabalho; prestar atendimento aos alunos e suas famílias via WhatsApp em qualquer horário, criando e/ou aumentado sentimentos como os de medo, ansiedade e insegurança pelo desconhecido; além de outras questões.

Destarte, a crescente carga horária de trabalho dos professores não é acompanhada pelo aumento salarial, nem mesmo pelo apoio de infraestrutura tais como acesso a melhores pacotes de internet, compra ou reparo de computadores pessoais, auxílio para pagar energia, compra de cadeira e mesa apropriadas. É importante ofertar condições adequadas para que os docentes possam realizar suas atividades com qualidade pois isso influencia na função principal da escola que é processo do ensino e da aprendizagem.

Essa intensificação vem acompanhada do desafio que estes professores enfrentaram pela falta de formação para o uso das tecnologias digitais, uma vez que até a chegada da pandemia esse tipo de formação era incipiente nos sistemas de ensino. No entanto, na pesquisa realizada, constatamos que a Secretaria Municipal de Educação de Santa Vitória ofereceu 
cursos de formação tecnológica para todos os professores da rede que, segundo as professoras, foram produtivos. Entretanto, o fato de terem sido oferecidos de forma aligeirada, em função da urgência do momento, muitas dúvidas e inseguranças foram sentidas por elas durante a utilização dos recursos pedagógicos digitais.

A partir desses olhares, verificamos que há uma necessidade premente de uma boa formação das professoras, o que corrobora com a uma condição sine qua non para o desenvolvimento no processo de aprendizagem das crianças.

O ambiente escolar deve reestruturar os objetivos para o processo de ensino e aprendizagem; para isso, a formação continuada, como aperfeiçoamento profissional dos educadores, sob o uso das ferramentas digitais e sociais disponíveis, é de suma importância para ativação de um processo educacional mais significativo (ABRANTES e SOUZA, 2016, p. 200).

Para complementar a formação oferecida pela Secretaria Municipal de Educação, 23 docentes sentiram necessidade de buscar também, por conta própria, outras possibilidades de formação continuada sobre as tecnologias digitais. Para a melhoria de suas habilidades da profissão docente em tempos de REANP, elas buscaram conhecimentos em vídeos na internet, tutoriais, em conversas com outras professoras, dentre outros recursos.

Foi muito difícil, principalmente no começo. Mas as professoras se uniram. Montamos grupos de estudo e pesquisa de atividades para troca de experiências; assim, quem tinha mais facilidade, ajudava as outras. Pedi ajuda de familiares e amigos que tinham facilidade com tecnologias, entrei em grupos nacionais de Educação Infantil e entrei em cursos oferecidos pelo Ministério da Educação. (Professora C da escola Beta).

Acho que todos nós, professores, estamos procurando todos os meios para que nossos alunos estejam aprendendo da melhor forma, procurando atividades que eles possam fazer em casa, procurando tudo que possa nos ajudar a reinventar a educação infantil. (Professora D da escola Ômega).

Para as professoras, o REANP foi o maior desafio que enfrentaram em suas carreiras, uma vez que precisaram reinventar o seu cotidiano, servindo-se de estratégias e táticas (CERTEAU, 1998) para fazer com que as aulas presenciais se tornassem, de um dia para outro, aulas não presenciais, por meio de ferramentas que muitas não tinham conhecimento até então. Essa reinvenção ocorre em todo o processo, inclusive no feedback e acompanhamento das atividades feitas pelas crianças, que se mostram as mais variadas:

Os pais enviam fotos das atividades feitas, fazem chamadas de vídeo ou ligações telefồnicas para tirarem dúvidas e para as crianças falarem o que estão tendo dificuldades. (Professora V da escola Alfa)

Recebo fotos da criança realizando as atividades, áudios e vídeos. $E$ alguns que não conseguem me enviar esse material no WhatsApp entregam as atividades na escola, no final do bimestre. (Professora L da escola Gama) 
Interação no Whatsapp da turma com vídeos explicativos e o retorno é no grupo mesmo, através de vídeo e áudio gravados pela família. Também para estreitar a distância, duas vezes na semana, temos encontros online. (Professora J da escola Gama)

Sobre a participação dos pais, também foi destacado pelas professoras como tem sido o processo de conscientizar as famílias da necessidade de colaboração no processo de ensino e aprendizagem. Ressaltaram ainda que ficar longe das crianças tem sido um grande desafio.

\section{Aplicar as atividades sempre pensando no material que as crianças têm em casa e ter que convencer os pais da importância de participação e realização das atividades, tem sido um grande desafio (Professora $\mathrm{E}$ da escola Gama)}

Como já abordado ao longo desse artigo, nem todas as famílias têm acesso à internet, e quando têm, não é de boa qualidade. Esse é o reflexo da desigualdade social que só tem crescido com o contexto pandêmico e para essas crianças que não conseguem acompanhar o REANP, as escolas precisaram adotar alternativas, uma vez que ter acesso à educação escolar é direito de todos. No entanto, as professoras afirmaram que 16,7\% de crianças estão sem nenhum atendimento, ou seja, não estão realizando ou sendo orientadas em relação a nenhum tipo de atividade de aprendizagem.

\section{Considerações Finais}

A oferta do Regime Especial de Atividades Não Presenciais (REANP) para a educação infantil vem apresentando muitos desafios dentre os quais destaca-se a falta de condições objetivas para viabilizar o ensino e aprendizagem, uma vez que a garantia de uma educação de qualidade em tempos de pandemia significa o direito de todos os professores e alunos terem acesso à internet com qualidade, bem como ter domínio no manejo de aplicativos softwares e plataformas digitais, o que ainda está distante da realidade de muitos professores e familiares.

Percebemos que as professoras, mesmo em condições precárias, continuam buscando alternativas para fazer com que as crianças possam continuar construindo conhecimentos, seja pela utilização de recursos tecnológicos, ainda que incipientes, seja na oferta de material impresso, para os que estão excluídos do universo virtual. Nessa conjuntura, que é tão incerta, as professoras, com intensa carga horária de trabalho, precisaram mudar as suas rotinas para não perderem o vínculo com seus alunos e possibilitar a eles a continuidade do processo formativo.

Em meio a essas condições adversas, há que se considerar uma questão que deve ser o eixo central de toda essa discussão: a afirmação da criança como sujeito de direitos, dentre eles o direito à educação de qualidade, social e historicamente referenciada. No entanto, a pesquisa aponta que esse direito não tem sido garantido e a pandemia deixou à mostra o quanto as nossas crianças têm sido vítimas da desigualdade social. 


\section{Referências}

ABRANTES, M.G.L., SOUSA, R.P. Formação continuada e conectivismo: um estudo de caso referente às transformações da prática pedagógica no discurso do professor. In: SOUSA, RP., et al., orgs. Teorias e práticas em tecnologias educacionais [online]. Campina Grande:

EDUEPB, 2016. Disponível em: https://static.scielo.org/scielobooks/fp 86k/pdf/sousa9788578793265.pdf. Acesso em 22 jul. 2021.

BRASIL. Ministério da Educação. Portaria nº 343, de 17 de março de 2020. Dispõe sobre a substituição das aulas presenciais por aulas em meios digitais enquanto durar a situação de pandemia do Novo Coronavírus - COVID-19. Diário Oficial da União, Brasília, DF, ed. 53, 18 mar. 2020. Seção 01, p. 39.

CERTEAU, M. de. A invenção do cotidiano: artes do fazer. Tradução de Ephraim Ferreira Alves. 3. ed. Petrópolis, Vozes, 1998.

HODGES, C. et al. The difference between emergency remote teaching and online learning. EDUCAUSE Review. 27 mar. 2020. Disponível em: https://er.educause.edu/articles/2020/3/the-differencebetween-emergency-remote-teaching-and-online-learning. Acesso em 30 ago. 2021.

FLACSO. Auxílio emergencial: Com benefício reduzido em 202 1, Brasil terá 61 milhões na pobreza. 23 de abril de 2021. Disponível em: https://flacso.org.br/?p=25063. Acesso em 28 ago. 2021.

FUNDAÇÃO CARLOS CHAGAS. Pesquisa: Educação escolar em tempos de pandemia na visão de professoras/es da Educação Básica. Informe nº 1, 2020, p. 1-5. Disponível em: https://www.fcc.org.br/fcc/educacao-pesquisa/educacao-escolar-em-tempos-de-pandemiainforme-n-1. Acesso em: 27 mai. 2021.

GEMAQUE. A. A pandemia agravou a desigualdade de renda e a pobreza no Brasil. Ecodebate. 21 maio 2021. Disponível em: https://www.ecodebate.com.br/2021/05/21/a-pandemia-agravou-adesigualdade-de-renda-e-a-pobreza-no-brasil/. Acesso em: 01 mai. 2021.

GESTRADO. Grupo de Estudos Sobre Política Educacional e Trabalho Docente. Relatório Técnico. Trabalho Docente em Tempos de Pandemia. Belo Horizonte: UFMG, 2020.

IBGE. PNAD Contínua TIC 2019: internet chega a 82,7\% dos domicílios do país. Agência IBGE Notícias, Editoria: Estatísticas sociais, 21/04/2021. Disponível em: https://censos.ibge.gov.br/2013-agencia-de-noticias/releases/30521-pnad-continua-tic2019-internet-chega-a-82-7-dos-domicilios-do-pais.html. Acesso em: 13 de agosto de 2021.

KRAMER, Sônia. As crianças de 0 a 6 anos nas políticas educacionais no Brasil: educação infantil e/é fundamental. Educ. Soc., Campinas, vol. 27, n. 96 - Especial, p. 797-818, out. 2006. Disponível em: https://www.scielo.br/j/es/a/Vc4sdh6KwCDyQPvGGY8Tkmn/?lang=pt\&format=pdf. Acesso em: 17 de maio de 2021. DOI: https://doi.org/10.1590/s0101-73302006000300009.

KRAWCZYK, N., LOMBARDI, J. C. (Orgs.). O golpe de 2016 e a educação no Brasil. Uberlândia: Navegando Publicações, 2018.

MARX, K. O capital: a crítica da economia política: Livro 1: o processo de produção do capital. Trad. Rubens Enderle. São Paulo: Boitempo, 2013. 
MINAS GERAIS. Comitê Extraordinário de COVID-19. Deliberação N. 18 de 22 de março de 2020. Suspende por tempo indeterminado as atividades presenciais de educação escolar básica. Publicada em 22/03/2020. Disponível em https://www2.educacao.mg.gov.br/images/stories/2020/INSPECAO ESCOLAR/Boletim _maio/DELIB._COVID-19_N\%C2\%BA_18_20.pdf. Acesso em: ago. 2021.

MONTAÑO. C. Pobreza, "questão social” e seu enfrentamento. Serviço Social \& Sociedade, São Paulo, n. 110, p. 270-287, abr./jun. 2012. Disponível em:

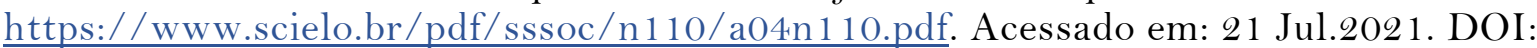
https://doi.org/10.1590/s0101-66282012000200004.

OLIVEIRA, D. A. PEREIRA JÚNIOR, E. A. Trabalho docente em tempos de pandemia: mais um retrato da desigualdade educacional brasileira. Revista Retratos da Escola, Brasília, v. 14, n. 30, p. 719-735, set./dez. 2020. Disponível em:

https://anped.org.br/sites/default/files/images/cnte relatorio da pesquisa covid gestrad o v02.pdf. Acesso em 28 mai. 2021. DOI: https://doi.org/10.22420/rde.v14i30.1212.

PARO, V. A divisão social do trabalho é a causadora da desigualdade no capitalismo. Pitacos Teóricos, 02/02/2020. Disponível em: https://www.vitorparo.com.br/8-a-divisao-social-dotrabalho-e-a-causadora-da-desigualdade-no-capitalismo/. Acesso em: 07 Ago. 2021.

PRESTES, L. Diferença no enfrentamento da pandemia: básico público e privado. CNU. 24 set. 2020. Disponível em: https://www.uninter.com/noticias/diferenca-no-enfrentamentoda-pandemia-basico-publico-e-privado. Acesso em 02 jun. 2021.

SANTA VITÓRIA. Decreto PM/No. 9.205/2020 de 16 de outubro de 2020 que disciplina o funcionamento das atividades propostas pela Onda Verde do Plano Minas Consciente, determina a suspensão das aulas presenciais nos estabelecimentos públicos e privados do Município de Santa Vitória para evitar a disseminação do coronavírus (Covid-19), e determina outras providências.

SAVIANI, D.; GALVÃO, A. C. "Educação na Pandemia: a falácia do ensino remoto". Universidade e Sociedade ANDES-SN, ano XXXI, janeiro, 2021, p. 36-49. Disponível em: https://www.sintese.org.br/2021/03/16/educacao-na-pandemia-a-falacia-do-ensinoremoto. Acesso em 28 jun. 2021.

UNICEF. Crianças de 6 a 10 anos são as mais afetadas pela exclusão escolar na pandemia, alertam UNICEF e Cenpec Educação. 29 abril 2021. Brasília (DF): Escritório da Representação do UNICEF no Brasil; 2021. Disponível em: https://www.unicef.org/brazil/comunicados-deimprensa/criancas-de-6-10-anos-sao-mais-afetadas-pela-exclusao-escolar-na-pandemia. Acesso em: 07 jul. 2021.

VIGOTSKII, L. S. Aprendizagem e desenvolvimento intelectual na idade escolar. In: VIGOTSKII, L. S., LURIA, A. R., LEONTIEV, A. N. Linguagem, desenvolvimento e aprendizagem. Tradução de: Maria da Pena Villalobos. - 11 a edição - São Paulo: Editora Ícone, 2010. 